\title{
Discurso de trabajadores sociales acerca de la desigualdad social: una lectura ética
}

\author{
Ruth Lizana Ibaceta*
}

RESUMEN

El presente artículo presenta las principales conclusiones a las que se llega luego de realizar una investigación documental, cuyo objetivo fue comprender los planteamientos éticos de los trabajadores sociales, a través de la revisión de las ponencias presentadas en el $33^{\circ}$ Congreso Mundial de Escuelas de Trabajo Social, respecto de la desigualdad social. Para acercarse a este discurso ético, se transforma matriz de análisis ético: ver - juzgar - actuar, en matriz de análisis de contenidos, construyendo un plan de análisis a partir de categorías pre definidas.

Palabras clave: Trabajo Social - ética - desigualdad social

\section{Declaração de trabalhadores social na desigualdade social: Uma leitura ética}

\section{RESUMO}

O artigo apresenta as principais conclusões após a realização de pesquisa documental, cujo objetivo foi compreender as considerações éticas dos assistentes sociais através da revisão dos trabalhos apresentados no $33^{\circ}$ Congresso Mundial de Escolas de Serviço Social com relação à desigualdade social. Para abordar esse discurso ético, torna-se uma matriz de análise ética: ver - julgar - agir, matriz de análise de conteúdo, construindo um plano de teste a partir de categorias pré-definidas.

Palabras chave: Trabalho social - a ética - desigualdade social

Social workers statement on the social inequality: An ethical reading

\section{ABSTRACT}

This article presents the main conclusions reached after conducting documentary research, whose aim was to understand the ethical considerations of social workers through the revision of the papers presented

* Chilena. Trabajadora Social. Magíster en Ética Social y Desarrollo Humano. Directora Escuela Trabajo Social Universidad Católica Silva Henríquez.

Correo electrónico: rlizana @ucsh.cl 
at the 33 th World Congress of Schools of Social Work with respect to social inequality. To approach this ethical discourse, it becomes an ethical analysis matrix: see - judge - act, content analysis matrix, constructing a test plan from pre-defined categories.

Key words: Social Work - ethics - social inequality 


\section{Antecedentes}

La tesis en que se basa este artículo aborda la temática de la desigualdad social, desde el Trabajo Social, a partir del análisis documental. Para ello se seleccionaron cincuenta y nueve ponencias sudamericanas, que participaron en el $33^{\circ}$ Congreso Mundial de Escuelas de Trabajo Social, que se desarrollara en Chile el año 2006.

La desigualdad social es hoy reconocida por distintos actores como un escándalo en sociedades como las nuestras, con elevadas tasas de crecimiento económico y con un grave problema de distribución de la riqueza. Sociedades fragilizadas donde los sectores más pobres suman estas desigualdades, que se manifiestan en lo que podría denominarse la cuestión social.

Sin lugar a dudas, el tema ético está a la base de la preocupación por la contradicción que vivimos como sociedad latinoamericana: crecimiento versus inequidad, exclusión social versus integración social, extrema pobreza versus extrema riqueza, entre otras contradicciones. En América Latina estas tensiones cobran especial relevancia dada las desigualdades sociales con las que vive un sector importante de su población.

Por otra parte, podemos señalar que la ética es constitutiva de la identidad del Trabajo Social. Reconocemos que "en las profesiones como en los individuos, la identidad está influida por un conjunto de factores y se constituye en relación dialéctica con una sociedad, un periodo histórico y una cultura que la van configurando permanentemente" (Aylwin, 1999), siendo la ética uno de esos elementos que hoy se releva. El componente ético político del Trabajo Social es reconocido por diversos autores. En el contexto chileno podemos mencionar a: Aylwin (1997); Matus (2002); Aguayo, López y Quiroz (2007); Sánchez (2001), entre otras trabajadoras sociales que han abordado el tema.

La realidad de desigualdad social ha sido siempre una preocupación para el Trabajo Social, podemos encontrar ya en los orígenes de la profesión un marcado interés por abordar dichas situaciones. La llamada cuestión social, espacio en que se expresa de manera flagrante la desigualdad social (Netto 2006), ha sido históricamente objeto constitutivo del quehacer del Trabajo Social Latinoamericano.

A decir de Netto (2006) el Trabajo Social latinoamericano está comprometido con la igualdad social, entendiéndola como única 
condición capaz de propiciar a todos y a cada uno de los individuos sociales las condiciones para su libre desarrollo. Las expresiones de la desigualdad social son una realidad que los trabajadores sociales conocemos de muy cerca, las distancias o diferencias bajo las cuales se desarrolla la vida de las personas se constituye en el espacio del quehacer del Trabajo Social. Desde allí es que surgen como desafíos éticos lograr avanzar en la consecución de una sociedad más igualitaria; como asegurar a las personas, grupos y comunidades la igualdad de oportunidades, que nos permitan avanzar hacia la construcción de sociedades más justas, donde cada uno pueda realizar sus capacidades, reconociendo que somos seres diversos y que vivimos en sociedades plurales.

La pregunta que guía la investigación refiere a ¿cuál es planteamiento ético, de los Trabajadores Sociales ponencistas del 33 Congreso Mundial de Escuelas de Trabajo Social, respecto de la desigualdad social en América Latina?

\section{Método de discernimiento ético: Ver - Juzgar - Actuar}

Este método proveniente de la vertiente religiosa para discernir la realidad, es posible también utilizarlo en el discernimiento ético de la realidad social, más allá del discernimiento teológico. Para el análisis de las ponencias seleccionadas se utilizó este método, dado que se muestra absolutamente coherente con la tradición del Trabajo Social, en tanto es una disciplina que se desarrolla en una realidad determinada, de la cual es capaz de dar cuenta (VER). Frente a esa realidad emite un juicio (JUZGAR) que consecuentemente lo lleva a proponer formas de transformación de dicha realidad (ACTUAR).

"El discernimiento teológico del ver-juzgar-actuar tiene sus raíces en Mater et Magistra (1961), N²36; Octogésima Adveniens (1971), N4." (Mifsud, 2006: 27). Es conocido como método pastoral del Movimiento de la Acción Católica (Padre Cardijn) donde se proponían tres pasos de observación de la realidad, reflexionar sobre ella, para proceder con una práctica consecuente. Este método fue asumido por la Iglesia Católica en el campo de lo social (Mifsud, 2006)

Es desde esta triple vertiente: ver - juzgar - actuar, que se busca develar la eticidad de los discursos de los trabajadores sociales, a partir de una matriz analítica inspirada en este método de discernir éticamente la realidad. 
En un breve resumen se puede señalarque, el ver busca comprender el hecho sobre el cual se discierne, centrándose en cuáles son sus consecuencias éticas; en el juzgar se busca reconocer los valores que están implicados en el hecho y se emite el juicio ético; en el actuar se presenta la acción ética transformadora.

Es así como la metodología busca capturar los fundamentos discursivos de los trabajadores sociales, a través del análisis de contenidos (Cea D`Ancona, 2001) en que se pone el relato en una situación no pensada por su autor, realizando una meta lectura a partir de una matriz diseñada para dar cuenta de los objetivos que guían la investigación, constituyéndose así en una investigación de segundo orden. "El asumir la realidad social como constituida de forma eminentemente lingüística lleva a privilegiar el uso de textos - cristalizaciones de sentido - en el trabajo de investigación" (Ramos, 2005) En tal sentido, la observación versa sobre todas las realizaciones que dan cuenta de los acontecimientos y las ideas humanas, o son producto de la vida social en cuanto registran o reflejan esta.

El método Ver, Juzgar, Actuar propone tres mediaciones (Laguna, 2004)

- Mediación socio-analítica (ver): contempla el lado del mundo del excluido. Procura entender las causas de la marginación.

- Mediación hermenéutica (juzgar): contempla el lado del mundo de Dios. Procura ver cuál es el plan divino en relación con el excluido.

- Mediación práctica (actuar): contempla el lado de la acción e intenta descubrir las líneas operativas para superar la exclusión de acuerdo con el plan de Dios.

Desde este método se recogen las tres mediaciones propuestas y desde allí se construyen preguntas que den cuenta de la existencia de elementos descriptivos, normativos y proyectivos en las ponencias de los trabajadores sociales. Ello se sintetiza en cuadro siguiente: 


\begin{tabular}{|c|c|c|}
\hline $\begin{array}{l}\text { MEDIACIÓN SOCIO - } \\
\text { ANALÍTICA (elementos } \\
\text { descriptivos) }\end{array}$ & $\begin{array}{l}\text { MEDIACIÓN } \\
\text { HERMENEÚTICA } \\
\text { (elementos normativos) }\end{array}$ & $\begin{array}{l}\text { MEDIACIÓN } \\
\text { PRÁCTICA (elementos } \\
\text { proyectivos) }\end{array}$ \\
\hline $\begin{array}{l}\text { ¿Cómo es presentado el } \\
\text { tema de la desigualdad } \\
\text { social por los } \\
\text { trabajadores sociales, } \\
\text { en las ponencias } \\
\text { seleccionadas? }\end{array}$ & $\begin{array}{l}\text { ¿Cuál es el juicio ético } \\
\text { que está presente en las } \\
\text { ponencias, respecto de la } \\
\text { realidad social? } \\
\text { ¿Se apela a alguna teoría } \\
\text { ética? } \\
\text { ¿Cuáles son los valores } \\
\text { profesionales que se } \\
\text { relevan en las ponencias? }\end{array}$ & $\begin{array}{l}\text { ¿Qué intervención } \\
\text { social proponen los } \\
\text { trabajadores sociales, } \\
\text { en las ponencias } \\
\text { seleccionadas? } \\
\text { ¿Qué desafíos éticos } \\
\text { plantean al Trabajo } \\
\text { Social, los ponencistas? }\end{array}$ \\
\hline
\end{tabular}

Es desde esta matriz y las mediaciones propuestas que surgen las siguientes categorías de análisis:

\begin{tabular}{|l|l|}
\hline CATEGORÍA & DEFINICIÓN \\
\hline $\begin{array}{l}\text { Desigualdad } \\
\text { social }\end{array}$ & $\begin{array}{l}\text { Aborda cómo es representada la desigualdad social, cómo se } \\
\text { define, a quién o qué se atribuye, entre otros. }\end{array}$ \\
\hline Juicio ético & $\begin{array}{l}\text { Refiere a como es valorada esta realidad (desigualdad social), } \\
\text { a mandatos, reglas, orientaciones para el discernimiento de } \\
\text { la realidad. Corresponde a los valores y/o principios que son } \\
\text { relevados en las ponencias respecto de la desigualdad. }\end{array}$ \\
\hline Teoría ética & $\begin{array}{l}\text { Referencia del autor a ciertas teorías o corrientes éticas que } \\
\text { subyacen en los discursos. Busca identificar el reconocimiento } \\
\text { de teorías éticas contemporáneas en el discurso de los } \\
\text { trabajadores sociales. }\end{array}$ \\
\hline $\begin{array}{l}\text { Propuestas } \\
\text { de } \\
\text { intervención } \\
\text { social }\end{array}$ & $\begin{array}{l}\text { Corresponde al momento de la acción transformadora y las } \\
\text { distintas propuestas de intervención que se realizan desde el } \\
\text { Trabajo Social y también a quienes atribuyen la responsabilidad } \\
\text { de intervenir, desde que lugar social (público, privado). }\end{array}$ \\
\hline $\begin{array}{l}\text { Desafíos } \\
\text { éticos }\end{array}$ & $\begin{array}{l}\text { Refiere a las aspiraciones, propuestas, que apelan a la ética de } \\
\text { los trabajadores sociales, como tarea pendiente y alternativa de } \\
\text { intervención. }\end{array}$ \\
\hline
\end{tabular}

\section{Principales resultados}

Debido a razones de espacio, para efectos de este artículo presentaremos aquellos resultados que refieren a las categorías juicio ético y desafíos éticos.

A través del trabajo con la categoría juicio ético, se busca reconocer como es valorada éticamente esta realidad de desigualdad social, a la vez distinguir las teorías éticas que son invocadas en las ponencias analizadas.

Lo primero que nos muestran las ponencias es el reconocimiento que hacen los profesionales de pertenecer a un ethos profesional determinado: "Los trabajadores sociales en tanto profesionales, no pueden 
desligarse de su vocación y responsabilidades y por tanto de los deberes morales de la profesión. En palabras de Cortina, se trata de una pregunta que colocará en primer plano las relaciones de nuestro ethos personal como nuestro ethos profesional en un horizonte de compatibilidad, congruencia e integridad." (P1)

Este ethos se ubica en el mundo de la vida y sería aquello que le da sentido a su quehacer y la hace reconocible: "para el trabajador social el bienestar humano y la autonomía de las personas" (P1)

Lo anterior pone al trabajo social en un horizonte utópico, donde la búsqueda por una sociedad más justa e igualitaria sería el principal mandato deontológico: "Porque la certeza de que las utopías de dignidad no han fenecido, mantiene la imperecedera llama que da fuerza a las luchas actuales y futuras en pos de los cambios deseados." (P2)

En las ponencias seleccionadas, es posible reconocer que se emiten juicios principalmente respecto del modelo de desarrollo de la mayoría de los países latinoamericanos (neoliberal), y también respecto del rol que ha desarrollado el Trabajo Social frente a él.

Respecto del modelo neoliberal, se señala que es generador de desigualdades y frente a estas se da una lectura fragmentada de la realidad. El rol del Estado se encuentra disminuido y desprovisto de un enfoque de derechos, que permita garantizar el bienestar mínimo a todas las personas. Un Estado que antepone los intereses económicos de particulares, generando mayor pobreza y un estancamiento en las metas sociales: "el modelo de desarrollo actual ha generado más pobreza que riqueza para la mayor parte de los colombianos. Se puede calificar como un modelo que no favorece la equidad. Todo indica que este modelo, marcadamente neoliberal, que se sustenta en las necesidades del capital financiero globalizado, no es coincidente con las urgencias en materia de desarrollo que tiene el país, o por lo menos no favorece la superación de los rezagos en materia social y económica." (P3)

Los procesos democratizadores se ven en riesgo, pierden legitimidad en sociedades donde existe la desigualdad, siendo una de las consideraciones éticas frente al modelo, el que: "Los principios de costo-beneficio, eficiencia y eficacia para responder a los procesos más globales de inserción del país en la economía global opacan los objetivos de contribución a los procesos de democratización de la sociedad." (P6)

Surge desde las ponencias un fuerte cuestionamiento a la posición que ocupan los sujetos que viven en situaciones de vulnerabilidad, tal como se expresa en el siguiente párrafo: "Las 
muchedumbres: nómadas en sus propias tierras, habitantes de los no lugares que pululan no sólo en las periferias sino en los centros mismos del imperio, tienen su propia libertad: la de ser famélicos mortales que están liberados a la vulneración, la condena, el miedo, la incertidumbre, la culpa, la nada." (P9)

Asimismo a juicio de los ponencistas, el impacto del modelo neoliberal en los grupos sociales no ha sido menor, siendo la inequitativa distribución de la riqueza uno de los pilares en los que funda este modelo: "sin lugar a dudas en América Latina persiste un alto grado de inequidad, provocado por la concentración de la riqueza y la propiedad, por condiciones ocupacionales y de empleo cada vez más precarizadas, por un sistema social que mantiene y reproduce la situación de desigualdad impidiendo una mejor distribución de la riqueza." (P13)

Esto se manifiesta en los distintos ámbitos de la vida de las personas, grupos y comunidades, señalan reiteradamente los ponencistas que: "la inequidad es un aspecto predominante de las sociedades latinoamericanas en casi todos los ámbitos de la vida: en cuanto al ingreso, empleo, oportunidad de acceso a la educación y a la salud, el acceso a los servicios básicos." (P13)

Ahora bien, un elemento complejo ha sido cómo este modelo ha ido naturalizando ciertos efectos perversos, que se ven desde los relatos como componentes propios del mismo y casi insalvables, generando paralización desde quienes intervienen en esta realidad: "El neoliberalismo se ha convertido en el 'paradigma de base', en todas las áreas del desarrollo de la sociedad chilena, muchas tesis neoliberales se han convertido en lo 'evidente' o natural quedando por consiguiente sustraídas de la discusión e invaden otros ámbitos de la vida humana con su supuesta obviedad. (Larraín, 1999). Precisamente el neoliberalismo se impone cada vez más como el modelo único e indiscutible." (P18)

Existe a juicio de los ponencistas abandono de una conceptualización más política de la desigualdad, por parte de los trabajadores sociales, el componente ético- político de la intervención profesional no aparece fuertemente vinculado a los discursos de quienes ejercen esta profesión: "Este escenario se vive con naturalidad por todos los actores involucrados aunque con distintas miradas o discursos según se trate, desde qué posición (capitales) o disposición (intereses) esté quien los analiza. Hace tanto tiempo que está presente esta problemática, que en vez de cambiar para bien, se transforma en otra cosa inesperada y terrible que hace que todo lo que ocurre sea habitual, cotidiano y normal." (P41)

Desde los espacios profesionales se ha llegado a naturalizar los efectos del modelo, ante la insustentabilidad de las intervenciones 
que se realizan: "Los esfuerzos y las inversiones han sido muchas. Sin embargo, se detecta que algo no está resultando, que algo sucede luego de que los proyectos terminan, luego de que se inaugura la nueva infraestructura o se obtiene el logro de los indicadores mínimos. Algo sucede, que, a pesar de la gran inversión, las transformaciones no son sustentables en el tiempo." (P48)

Surge así una fuerte crítica al ejercicio del rol profesional: "Los trabajadores sociales y las trabajadoras sociales, al igual que amplios sectores de población tienen expropiados hasta de sus propios sueños, se vieron autorreferenciados a sus propios mundos de sobrevivencia $y$ de vida ejerciendo - así fuera en su propio país o en el exilio- el trabajo social que les era posible dentro de los límites que les estaban dados: el del fragmento, la no praxis, el no discurso sistémico, el microfundamento sin macroexplicación." (P9)

El horizonte utópico se pierde, generando malestar identitario y crisis de sentido en los trabajadores sociales: "el desmantelamiento de los estados latinoamericanos, los impactos perversos de la mega deuda externa y los procesos de desestructuración, fragmentación y reterritorialización de nuestros países, frente a lo cual los trabajadores sociales y las trabajadoras sociales no hemos aún levantado - al menos no con gran entusiasmo ni de manera sostenida- bandera alguna de refundación del oficio que tanto nos gratifica pero que también nos duele." (P 9) Ello además se refleja en la sigue expresión: "Nuestra profesión ha perdido su capacidad de respuesta a las necesidades sociales en los actuales tiempos neoliberales y expresa una crisis de sentido donde la voluntad del profesional, se subordina a lo rutinario, a una política social orientada por una racionalidad técnica-instrumental, y sujeta a un orden social autoregulado por el mercado, donde resurgen las tendencias filantrópicas en la intervención social predominando las lógicas pragmáticas de lo posible."(P18)

¿Cómo comprendemos hoy la realidad social los trabajadores sociales?, ¿Cuál sería hoy la cuestión social?. Son preguntas que buscan volver la mirada al thelos profesional, entendido como el ser de la profesión.

Señalan los ponencistas que hoy es necesario comprender la realidad social desde la complejidad, revisando el actuar profesional, hoy, se señala, que principalmente se ha privilegiado una acción más asistencial: "una comprensión de la realidad como totalidad social contradictoria e históricamente producida." (P2). Ello además se refleja en lo siguiente: "La mirada al complejo mundo de la exclusión social suele hacerse desde parámetros mercantilistas e individualizadores. Esto es, por un lado, tiende a preocupar más cuánto se gasta para atender la exclusión social, que por qué se produce y cómo puede evitarse. Por otro 
lado, en gran medida se tiende a buscar responsabilidades individuales para justificar las situaciones de exclusión y correlativamente se ofrecen respuestas individuales para "salir" de ella." (P54)

El Trabajador Social se encuentra alejado efectivamente de aquellos espacios donde se toman decisiones de carácter político: "porque las decisiones en materia de inversión o intervención para el desarrollo del territorio, se reservan eminentemente para la decisión política, espacio donde los Trabajadores Sociales no tienen expedita participación, debido a su opción de privilegiar sus tareas técnico - profesionales." (P49)

Es necesario señalar que aparece latente en los discursos de la desigualdad social el tema del poder que ha permitido perpetuar el modelo: poder de quienes ostentan las ganancias de este y el "no poder" de quienes se ven invisibilizados: los sujetos, grupos, comunidades que viven los efectos del modelo, pero también los profesionales que buscan mitigar estos mismos efectos, a través de la intervención social, como es el caso de los Trabajadores Sociales.

Ambos, poder y no poder violentan igualmente las posibilidad de generar espacios de mayor equidad y construir sociedades más humanas, dado que por un lado, las personas tienden cada vez más a organizar su vida de acuerdo a sus opciones personales, dificultando la creación de un horizonte común que organice culturalmente la sociedad y por otro, se observa que el orden institucional opera en ámbitos cada vez más descentralizados, cobrando mayor importancia la articulación de procesos independientes y el manejo de la incertidumbre del entorno. (PNUD 2009: 14).

En esta transformación de los contextos sociales, se configuran como nuevas comprensiones de los problemas sociales, las practicas de los actores y también as estrategias de intervención profesional.

El deber profesional se constituye en uno de los elementos que se presenta en las ponencias, como sustrato del hacer del Trabajador Social como profesional que responde a lineamientos que se han construido históricamente: "Teorías deontológicas, que plantean que ciertos tipos de acción son inherentemente correctas o incorrectas, como una cuestión de principio. Este grupo de teorías se focaliza en satisfacer los propios deberes; respetar los derechos y la autonomía de otros y el tratar a otros con justicia igualitaria."(P43) 
Esto se refuerza en otras expresiones como la siguiente: "Todas las profesiones tienen un deber moral respecto de sus acciones, el médico debe responder ante la sociedad por la salud de la población, los trabajadores sociales por la justicia y bienestar de las personas, el abogado por los derechos y obligaciones ciudadanas y del Estado etcétera. El cumplimiento de estas obligaciones morales les permitirá una mayor o menor legitimidad ante la sociedad."(P1)

Se señala que este sentido del deber profesional es parte de la esencia del ser profesional: "Es la conciencia del deber que obliga a los hombres y mujeres a cumplir sus deberes traducidos en su labor profesional cotidiana."(P1)

Podría decirse que este deber ser es un discurso naturalizado. El deber marca la acción profesional, entendido muchas veces como este imperativo categórico, en lenguaje de Kant que movería el quehacer de los profesionales. Un deber ser que es dado y que el Trabajador Social respeta: "Cada trabajador social, educador, colaborador o adulto que trabaja con la infancia, tiene una responsabilidad social, la de examinar su práctica, repensarse como persona e identificar los paradigmas en los cuales se fundamente su vida personal y profesional."(P8)

Este hallazgo es coincidente con los estudios realizados por Miranda (2006); Aguayo, López y Quiroz (2007), pudiendo señalar que los ponencistas cuando refieren a teorías éticas que puedan fundamentar su acción, apelan a teorías deontológicas: "La teoría ética deontológica es la teoría dominante en la justificación de los principios éticos preferidos en el contexto del ranking general" (P43)

Este mandato puede incluso llevar al profesional a tensionar su relación con la institución donde ejerce: "Los derechos de los usuarios, mucho más que las normas propias de la institución, parece ser la fuente más segura de los principios éticos del obrar profesional, aún contra la institución o el sistema." (P43)

El mismo ponencista, expone que existe otro grupo de teorías que se denominan teoría teleológica, también llamada consecuencialistas: "Teorías teleológicas, que postulan que ciertas acciones deben ser realizadas porque son buenas a razón de sus consecuencias. Una orientación teleológica que ha influido al trabajo social es la teoría utilitarista (Reamer, 2001)." (P43)

En algunas ponencias aparece claramente que no siempre el Trabajador Social se maneja a partir de convicciones o principios abstractos, sino que aprecia las consecuencias que cada acción 
puede tener, buscando aquella que genere el menor impacto negativo: "Sarah Banks, quien realiza un análisis muy detenido de diferentes paradigmas éticos en relación con la intervención profesional del Trabajador Social insiste en la presencia de la matriz utilitarista en la estructura misma y en el ejercicio de la profesión. El principio de utilidad dicta que la acción más correcta es aquella que produce un mayor peso del bien sobre el mal. El trabajador social, afirma, no es un trabajador autónomo; él es contratado por agencias, trabaja dentro de unas reglas y procedimientos legales $y$ debe intervenir para fomentar el bien público o el bienestar de la sociedad en general. Por lo tanto, frente a decisiones éticas pone en juego principios éticos ligados a la utilidad, entendida como el mayor bienestar, y a la justicia." (P59)

Según la investigación realizada por Miranda (2006), se apela a la ética utilitarista para justificar principios éticos en situaciones específicas. A partir de esta distinción, aparece el tema de la autonomía versus heteronomía frente a las decisiones éticas: "la relación autonomía - heteronomía toma en cuenta las condiciones institucionales, bajo la premisa de que tanto en el campo interno del Trabajo Social, como en su contexto, encontramos componentes que marcan límites y posibilidades de intervención. En efecto, el proyecto político vigente y el marco institucional inmediato en el cual el profesional desarrolla su tarea, son componentes centrales a considerar en la delimitación de la autonomía. Las instituciones, sin determinar de modo absoluto nuestras estrategias -en tanto vehiculizan estrategias más amplias, que trascienden al Trabajo Socialoperan como marco del mismo. Ellas se plasman en organizaciones que tienen normativas, recursos, políticas, que posibilitan o limitan, potencian o impugnan, en síntesis, dan el marco particular desde el cual el profesional debe pensar e implementar su intervención." (P5)

Esta es una tensión que aparece planteada en diversos estudios y publicaciones respecto de cuán autónomos son los trabajadores sociales cuando toman decisiones. Qué grado de influencia tiene el trabajar bajo dependencia institucional es una pregunta recurrente, si pensamos que un alto porcentaje de los profesionales realizan este tipo de trabajo.

Cuando los ponencistas refieren a teorías éticas, generalmente lo hacen respecto de teorías contemporáneas, principalmente a aquellas que aparecen desde la raíz Habermasiana, vinculada a la ética comunicativa. Varios de ellos refieren a la ética del discurso, como base para la existencia de una ética cívica y una ética de mínimos. 
Al preguntarse respecto de cuáles serían aquellos mínimos, surgen los Derechos Humanos, reconocido como acuerdo socio histórico que se ha dado la sociedad occidental, como propuesta de realización, en sus distintas generaciones.

Respecto de la ética del discurso en otra se argumenta que: "el neosocialismo dialógico (conocida también como ética discursiva o ética comunicativa), tradición filosófica que tiene sus orígenes en los años setenta del siglo XX en Alemania, a partir de los trabajos de Karl-Otto Apel y Jürgen Habermas, que confluyen en el Instituto de Investigaciones de la Universidad de Frankfurt, en el sentido que la ética discursiva se asume como heredera de la teoría kantiana aunque va más allá tratando de superar los límites monológicos implícitos en ella, dicho de otro modo, la ética discursiva reconoce de entrada su prosapia kantiana, pero advirtiendo a la vez que se trata de una reformulación de la misma con medios tomados de la teoría de la comunicación (Sobrevilla, 2005: 19), esto es, mediante lo dialógico y lo intersubjetivamente justificable la fundamentación de la universalización de las normas correctas (Jongitud, 2001, p. 14; Cfr. Salvat, 2002a, pp. 144 y ss.)." (P4)

Respecto de la ética cívica los ponencistas argumentan que: “... se trata de explicar la idea según la cual "una persona es alguien que puede ser un ciudadano, entendida como libre e igual" (Rawls, 1996a, pp. 29, 31). Según Rawls, la persona (aquel que habita en una sociedad entendida como un sistema equitativo de cooperación) "reúne cuatro condiciones (libertad, igualdad, moralidad y racionalidad)" (Zapata, 2001, p. 91), que configuran su autonomía. De ahí se colige que las personas tienen dos facultades morales, comparable con el principio ontológico, según la cual todos los seres humanos llegan al mundo equipados ya con una competencia comunicativa. Estas facultades morales se imbrican, a su vez, con otras dos ideas fundamentales: lo razonable y lo racional." (P8) Ello se evidencia además en que: "A ello se le suma la actitud dialógica, que sería el modo correcto de vinculación entre interlocutores para la construcción de normas comunes y establecimiento de acuerdos. Esta actitud, tiene como requisito la voluntad de entendimiento y el reconocimiento del otro como interlocutor válido, amén de un conjunto de reglas racionales y éticas que las partes se comprometen a reconocer y a respetar. En esta perspectiva, la ética cívica, podría concebirse como una "conquista" de las sociedades respecto de aquello que debe ser reconocido como deseado para todos y cada uno de sus ciudadanos, más allá de sus diferencias; y que éstos al mismo tiempo, se comprometen a respetar y defender." (P19) Además esto se ven en que: "Desde la perspectiva del entendimiento comunicativo, la idea de ciudadanía se erige desde ciertas cuestiones fundamentales: el entendimiento lingüístico como clave de las capacidades reflexivas, argumentativas - discursivas en los sujetos, que los convierte en ciudadanos, y la acción comunicativa como 
posibilidad en la que los distintos sujetos aceptan coordinar de modo interno sus planes y alcanzar sus objetivos, únicamente, a condición de que exista - o se alcance mediante negociación- un acuerdo sobre la situación y las consecuencias que cabe esperar" (P48)

Respecto de la ética de mínimos: ¿Cuáles son los mínimos éticos que debemos defender?" (P1)

Tal como lo señaláramos, la respuesta generalizada es poner los Derechos Humanos como esos mínimos a defender: "Los derechos a la alimentación, al trabajo, a la salud, a la educación, a la vivienda, entre los más importantes, deben ser considerados como bienes públicos, que se deben garantizar al conjunto de la población por su mera condición de ciudadanos. Si se desea fortalecer realmente el funcionamiento democrático de la sociedad, resulta suicida subalternizar estos derechos a la lógica del mercado, tal como se verificó en el período de hegemonía neoliberal." (P2) Ello además se evidencia en que: "La democracia basada en la ciudadanía excede el régimen político o el ejercicio de los derechos políticos, ella requiere ampliarse e incorporar otras dimensiones de los DD.HH; civiles, multiculturales, económicos y sociales. De allí se colige que el sujeto central de la democracia no sea el elector sino el ciudadano(...) Por nuestra parte, decimos que el pleno ejercicio de los DD.HH. (cuando menos de las tres generaciones) requieren tener el mismo nivel de urgencia e importancia, lo cual implica, otorgarle el mismo peso a las distintas dimensiones de la ciudadanía" (P4) Ello además se ve en que: "Los conceptos exclusión-vulnerabilidad-inclusión, conforman una trilogía constituida a partir del marco dado por los derechos políticos, civiles y sociales como elementos base para la construcción de sociedades integradas, como un todo interactivo, que permite incorporar el dinamismo que caracteriza las actuales relaciones sociales $y$, a la vez, las nuevas condiciones de desigualdad." (P40)

Los ponencistas al mencionar teorías éticas contemporáneas, obviamente hacen mención a algunos autores que las representan, como Habermas, Rawls, Cortina. En algunas de las ponencias se exponen los planteamientos centrales de las teorías que inspiran, aspecto que no fue posible abordar en la investigación realizada, dada la magnitud y complejidad de las mismas.

Un aspecto a relevar es lo invisibilizada que queda la ética latinoamericana, dado que en ninguna de las ponencias revisadas se hace mención a autores latinoamericanos, ni a sus postulados.

Finalmente, los Trabajadores Sociales exponen algunos principios que consideran fundamentales y una serie de valores, que si bien 
son universales, son apropiados para el ejercicio profesional. Podemos mencionar entre ellos los Principios de: Respeto, libertad, justicia social, amorosidad y responsabilidad social: "Lo primero que evocamos al pensar en la ética, es la noción de respeto." (P25) Se dice que: "Además se debería considerar algunos principios básicos que será nuestro reto como educadores: Práctica del principio de la amorosidad, pues no es posible que un trabajador social no posea una relación amorosamente humana entre él y yo, entre el sujeto maestro y el sujeto niño (...) Cada trabajador social, educador, colaborador o adulto que trabaja con la infancia, tiene una responsabilidad social, la de examinar su práctica, repensarse como persona e identificar los paradigmas en los cuales se fundamente su vida personal y profesional. Se considera importante ejercer esta posición para todas las personas, principalmente para los que trabajamos con la infancia." (P16)

Y como valores: tolerancia, solidaridad y cuidado del otro: "La igualdad reclama la existencia de un conjunto de iguales obligaciones y derechos para toda la ciudadanía, tal como plantean Florisabel Rodríguez y Silvia Castro Méndez, este Valor hace referencia a la necesidad de crear oportunidades para todos, e incluye los valores de la tolerancia y la solidaridad (Rodríguez; Castro Méndez, 2001:190)." (P12)

Todos principios y valores que han acompañado el ejercicio profesional desde sus orígenes. De allí la necesidad de remirar la historia profesional y buscar en ella los elementos que puedan nutrir la ética de la profesión hoy día. Tal como se señala en las páginas iníciales de esta investigación y siguiendo a Nidia Aylwin (1999), se reitera que Trabajo Social es tributario de su historia y es posible reconocerse en ella.

\section{Conclusiones}

Al plantear las conclusiones surgen dos grandes aspectos: uno que dice relación con las propuestas de intervención social que es posible rescatar desde las ponencias y los desafíos éticos que enfrenta el Trabajo Social, frente al tema de la desigualdad social. En este punto, como señalamos al principio de este artículo, abordaremos los desafíos éticos para finalmente proponer pistas para avanzar en la discusión ética frente al tema de la desigualdad social, desde el espacio académico.

Se señala en las ponencias que es el mismo contexto que demanda éticamente al Trabajo Social, desde el reconocimiento de una realidad que desborda los antiguos diagnósticos por su complejidad: "El Trabajo Social profesional se sitúa en la actualidad en sociedades heterogéneas, "marcadas principalmente por el aumento de la 
desigualdad, las dificultades para el ejercicio pleno de derecho de la ciudadanía" (Castañeda, P., 2005: 75), entre otros elementos. Algunas dimensiones de ésta situación, para no concebirla como crisis, es la exclusión progresiva de sectores más amplios, los marcos de relación entre el estado mercado y la sociedad civil." (P34)

Cómo desafíos éticos hacia la formación profesional surge la necesidad de incorporar con mayor fuerza el componente ético en los planes curriculares de las Escuelas, permitiendo la emergencia del componente ético político, que hoy aparece desdibujado en los currículos, dotándolos de una identidad latinoamericana, lo anterior permitiría comprender las manifestaciones de la cuestión social y su implicancia en la intervención profesional, una ética comprometida con la superación de la desigualdad social, a través del respeto de los Derechos Humanos como mínimos éticos que nos permitirían vivir en sociedades plurales como las nuestras.

Lo anterior implicaría dotar a las nuevas generaciones de trabajadores sociales de una serie de recursos, dispositivos que les permitan asumir la profesión con un sentido crítico: "Es necesario no perder de vista que en los últimos 10 años el Trabajo Social atraviesa por un proceso creciente de acumulación de conocimientos que, aunque encuentre su locus en el medio académico, comienza a diseminarse significativamente fuera de las universidades. En este sentido es fundamental que los Asistentes Sociales aprehendan la realidad en su totalidad, pues solamente así podrán identificar las demandas emergentes y anticipar nuevas, creando formas de intervención y recalificando su hacer profesional." (P33)

Las competencias éticas, más allá del reconocimiento de ciertos valores, principios y normas para el ejercicio profesional, se constituyen hoy en exigencia. Exigencia de argumentar las decisiones, desde referentes teóricos, siendo este otro de los desafíos hacia la formación disciplinar: "Los estudiantes, y particularmente los practicantes, deben ser capaces de discutir críticamente el razonamiento tras sus decisiones discrecionales y ser capaces de sostener el escrutinio y el examen de colegas profesionales e instancias legales, justificando sus decisiones discrecionales en términos de estándares y valores profesionales. Esto es, sus justificaciones éticas deben estar amarradas a justificaciones normativas profesionales y estar en congruencia con lo que puede ser llamado el trabajador social "razonable". (P43)

El conocimiento de las teorías éticas se constituiría en un apoyo fundamental al momento de la toma de decisiones, por lo que se demanda fortalecer la enseñanza de la ética en la formación de los Trabajadores Sociales. 
El desarrollo disciplinar plantea dos grandes demandas, dada la complejidad de los social. Una de ellas es el contar con nuevos marcos teóricos que permitan explicar y comprender la realidad social, para luego intervenirla y la segunda es la investigación y su divulgación, constituyéndose en una tarea ineludible para la generación de conocimiento y avance disciplinar: "En una sociedad diversa, compleja, incierta, global, inequitativa como la propia de esta época de cambio, los profesionales y unidades académicas de Trabajo Social, tienen el deber de investigar y producir conocimiento a partir de estas realidades." (P53)

La dimensión ético política del Trabajo Social es el gran tema pendiente, se hace necesario re-pensar una ética latinoamericana que permita asumir los dolores y desafíos que nos plantea la realidad de desigualdad social que se viven en las sociedades latinoamericanas. Una ética que permita construir un ethos epocal propio, desde la historiografía latinoamericana. Una ética que permita a través del diálogo con un legítimo otro (reconocido como tal) escribir los anhelos de justicia e igualdad: "Hoy constituye un reto fundamental orientar la formación y el quehacer profesional en consonancia con una férrea lucha por la promoción, ampliación, defensa y exigibilidad de los derechos humanos, ya sea desde la acción profesional directa con las poblaciones meta de los servicios sociales, con el trabajo socioeducativo promocional con las organizaciones de la sociedad civil constructor de ciudadanías y desde las competencias en el campo de la gestión y formulación de las políticas sociales." (P2)

Los Derechos Humanos como sustrato ético de la acción profesional, son reconocidos como una fortaleza de los Trabajadores Sociales. Esto implica un compromiso con el otro al ser reconocido como un legítimo otro y la responsabilidad de la exigibilidad de sus derechos. Una interrogante que se plantea es saber si es hoy posible esta construcción, en medio de un modelo que fragmenta, discrimina, aísla y genera las mismas situaciones sobre las cuales la ética nos exige pronunciarnos.

Señala Carlos Eroles, en la ponencia presentada al Congreso, que el primer compromiso del Trabajo Social Latinoamericano, entendiéndolo aquí en clave de desafío ético - político sería la construcción de ciudadanía: "el ejercicio profesional del trabajador social debe endosar y favorecer la colectividad de las luchas sociales y la afirmación de los derechos - no como un fin en sí mismo-, pero como un principio orientador de la profesión en la dirección de la emancipación humana (no apenas política o social)." (P60) 
Sería posible hoy remirar el desafío ético político del Trabajo Social en América Latina en una clave de emancipación y pensar y vivir la ética desde ella.

Es así como se propone el surgimiento de la perspectiva de una ética situacional (Román, 2007) como respuesta frente a la naturalización de la desigualdad social y a la ausencia de un relato que nos vincule más propiamente con una ética latinoamericana, que se hace cargo de la complejidad de lo social, es a partir de ella que es posible reconocer las transformaciones sociales, tensionar el afán de universalización de la norma moral, versus las necesidades individuales de sujetos y grupos humanos, permitiendo la construcción de un proyecto profesional ético y político.

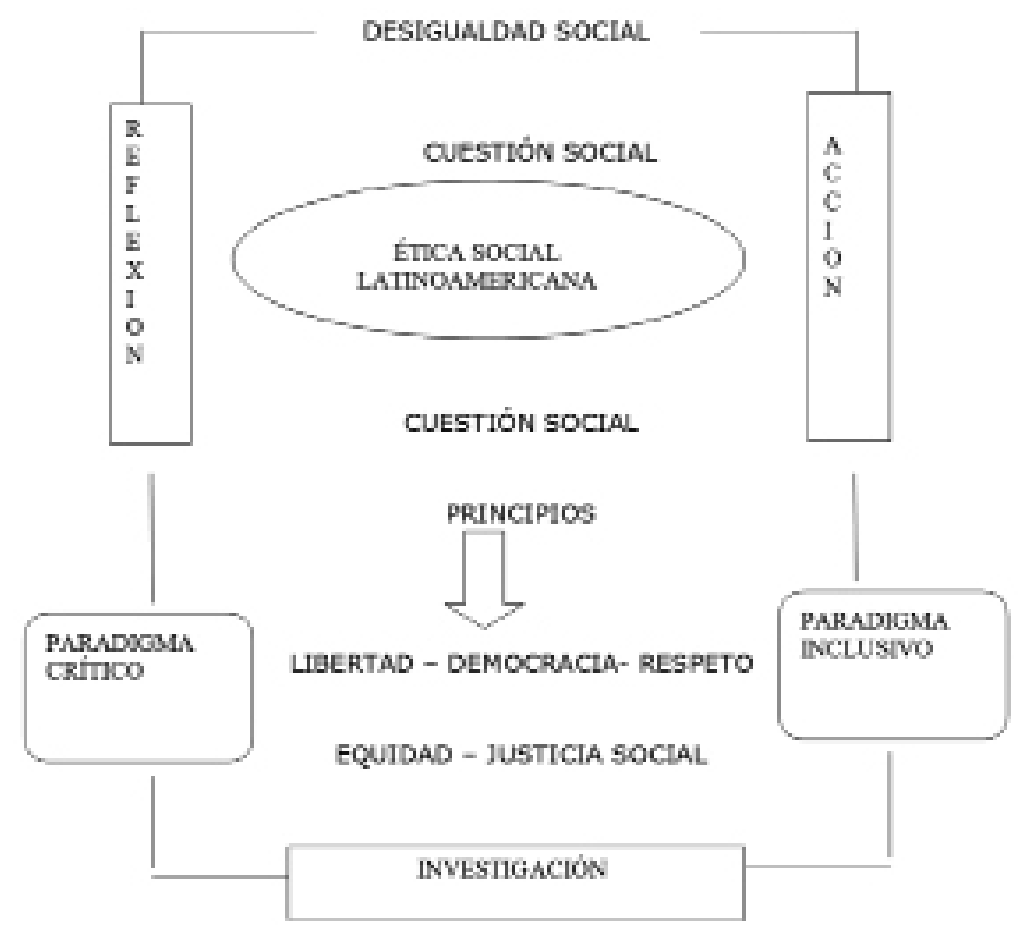

Al pretender, no sin dificultad, plantear alguna propuesta de cómo abordar desde el desarrollo disciplinar profesional el tema de la desigualdad social es que aparece la cuestión ética, haciendo una distinción entre dos vertientes (que se separan sólo por efectos pedagógicos, pero que conviven siendo parte de un todo), lo que en su conjunto denomino la experiencia profesional. En el siguiente cuadro a modo de síntesis es posible visualizarla. 
Finalmente, es posible sostener que una de estas vertientes, es la reflexión cuyas características la sitúan desde un paradigma crítico, complejo, sin perder lo metódico y riguroso y la otra vertiente es la acción, desde un paradigma de la inclusión, tendiente a la construcción de ciudadanía desde la legitimidad del otro, otro que ha sido construido, desde América Latina, como un sujeto oprimido. Los principios profesionales que se relevan son la libertad, la democracia, el respeto, la equidad y la justicia social, horizonte teleológico del Trabajo Social. Ambas, acción y reflexión se unen en la investigación, que busca conocer para transformar las situaciones de desigualdad.

\section{Referencias bibliográficas}

AGUAYO, C.; LÓPEZ, T.; OUIROZ, T. (2007) Ética y Trabajo Social en las voces de sus actores: Un estudio desde la Práctica Profesional. Colegio Asistentes Sociales de Chile.

AYLWIN, N. (1999) Identidad e historia profesional. Revista Perspectivas $N^{\circ} 8$. Escuela de Trabajo Social. Universidad Católica Silva Henríquez. Santiago de Chile.

(1997) Trabajo Social y Ética Profesional, Revista de Trabajo Social. N69 Escuela de Trabajo Social. Pontificia Universidad Católica de Santiago de Chile.

CEA D'ANCONA, M. (1996) Metodología cuantitativa: estrategias y técnicas de investigación social. Síntesis. Madrid.

LAGUNA, J. (2004) ¿De la liberación a la inclusión? Cuaderno Nº127 Centre d' Estudios Cristianisme i Justicia. Fundació Lluís Espinal. Barcelona.

MATUS, T. (2002) Propuestas Contemporáneas en Trabajo Social: Hacia una Intervención Polifónica. Espacio. Buenos Aires.

MIFSUD, T. (2006) Ethos Cotidiano. Un proceso de discernimiento. Universidad Alberto Hurtado. Santiago de Chile.

MIRANDA, P. (2006) Lo público sitiado. Recuperado en mayo de 2006. Disponible en: http://www.sociedadchilenadeteologia.cl/docs/valparaiso2011/pmiranda_lopublico-sitiado.pdf

NETTO, J. P. (2006) El orden social contemporáneo como desafío central. Conferencia Central $33^{\circ}$ Congreso Mundial de Trabajo Social. Santiago de Chile. 
PNUD (2009) Desarrollo Humano en Chile: La manera de hacer las cosas. Programa de las Naciones Unidas para el Desarrollo. Santiago de Chile.

RAMOS, C. (2005) Como investigan los sociólogos chilenos en los albores del siglo XXI: paradigmas y herramientas del oficio. Revista Persona y Sociedad, Vol. XIX. № 3. Universidad Albeto Hurtado. Santiago de Chile.

ROMÁN, M. (2007) Dilemas y paradojas: el contexto para la producción de una ética situacional y contingente. Ponencia presentada en la Quinta Conferencia de Trabajo Social Forense. Universidad Interamericana. Costa Rica.

SÁNCHEZ, D. (2001) Derechos Humanos y Exclusión: Una mirada desde el Trabajo Social. Revista Perspectivas $\mathrm{N}^{\circ} 10$, Escuela de Trabajo Social. Universidad Católica Silva Henríquez, Santiago de Chile. 